Please cite as: Kuppelwieser, Volker G. and Finsterwalder, Jörg (2016): Transformative Service Research and Service-Dominant Logic: Quo Vaditis? Journal of Retailing and Consumer Services, 28(1), 91-98 (http://dx.doi.org/10.1016/j.jretconser.2015.08.011).

\title{
TRANSFORMATIVE SERVICE RESEARCH AND SERVICE-DOMINANT LOGIC: QUO VADITIS?
}

\author{
Abstract \\ This paper takes a closer look at the emerging topic of transformative service research \\ (TSR) and compares its facets with the more established concept of the service-dominant logic \\ (SDL). The paper thus contributes to both theory development and practical application. This \\ work highlights the conceptual parallels in the two approaches, for example, their holistic \\ approach, their systems thinking, addressing entities or actors within such system(s), inclusion of \\ the wider environment, and their focus on the co-creative and interactive nature of well-being \\ generation and value co-creation. The paper also reveals some differences, for example TSR's \\ focus on eudaimonic and hedonic well-being outcomes vs. SDL's value co-creation. The paper \\ concludes that both perspectives have merits, but could benefit from being used integratively. By \\ comparing the areas of theory focus, practical application, value co-creation and co-destruction, \\ intentionality, well-being and value concepts, and TSR and SDL's "logic", the paper provides \\ suggestions for future research.
}

\section{Keywords}


Transformative Service Research; TSR; Service Dominant Logic; SDL 


\section{INTRODUCTION}

Transformative service research (TSR) has been labeled a "new area" in both consumer and service research (Rosenbaum et al., 2011, p. 5). It is defined as "the integration of consumer and service research that centers on creating uplifting changes and improvements in the wellbeing of consumer entities: individuals (consumers and employees), communities and the ecosystem” (Anderson et al., 2011, p. 3). This encompassing definition opens the field for a broad range of potential research topics and applications related to improving the welfare of individuals and groups embedded in social systems and ecosystems. However, TSR is in its infancy and only a few researchers have to date tried to explain, develop, and apply TSR in their research (e.g., Anderson et al., 2013; Rosenbaum et al., 2011).

Fisk et al. (1993) classify this early and first evolutionary stage as a discovery and risk taking phase in marketing research. In line with this early stage, the latest calls are for TSR research to provide "a conceptual framework that can serve as a catalyst for future research" (Anderson et al., 2013, p. 1209) in order to inform and motivate service researchers to engage in this area. This is in line with Ostrom et al.'s (2010, p. 5) earlier call to focus one of service science research’s future priorities on "improving well-being through transformative service" and "through cocreation of value".

Whilst most other research fields, such as social marketing, transformational consumer research (TCR), and service-dominant logic (S-D Logic or SDL), have moved beyond their embryonic beginnings and started on their next evolutionary step (Fisk et al., 1993), TSR adapts or includes research insights from related areas and other relevant disciplines. For example, social marketing's scope, goal, and use of the marketing mix seem very similar to TSR's approach toward resolving similar societal well-being issues. Additionally, the broadening of the 
service concept through the inclusion of the service sustainability notion (Edvardsson and Enquist, 2008; Grove et al., 1996; Shirahada and Fisk, 2011) has had an impact on the formulation of the TSR concept. Further, TSR has been conceptualized at the intersection of transformative consumer research and service research (Anderson et al., 2013). On the other hand, SDL offers a value concept (e.g., Vargo and Lusch, 2004), which seems similar to the creating of "uplifting changes and improvements" (Anderson et al., 2011, p. 3) found in TSR literature, thus masking the value of TSR's contribution. For example, when Ostrom et al. (2010) discuss improving well-being through transformative service research, they also mention the cocreation of value to achieve this. This potential intertwining of the concepts is further fuelled with statements, such as:

"Service consumption influences customer well-being, including life satisfaction, perceived quality of life, and overall happiness. Research that assists decision makers in understanding the value of these measures (...) is critical. (...) [I]t is also critical to design, improve, and scale service systems in a way that simultaneously enhances cocreation, lifetime value, and well-being” (Dagger cited in Ostrom et al., 2010, p. 10, italics added).

The emergence of TSR and its potential interweaving with other theoretical approaches might confuse researchers and hinder service science’s development as a discipline resolving “real problems" (Mick, 2006, p. 1). While scholarly inquiries into the role of services and service outcomes are gaining momentum (e.g., Echeverri and Skålén, 2011; Grönroos and Voima, 2013), current research still varies on how TSR should be considered in current thinking and in research models. This paper thus sets out to initiate a discussion on the theoretical TSR framework and its 
relationships to SDL. It aims at disentangling their interweavements and focuses on spinning the theoretical concepts' loose ends into a single strand.

This paper not only provides an overview of SDL as the most commonly used and highly cited concept in marketing over the last years (Thompson Reuters, 2014), but also compares TSR with SDL to deepen scholars' understanding of these approaches' potential relatedness, their research aims, and intended outcomes. In addition, it scrutinizes the connection between these concepts by subsequently conducting TSR-related research. As such, the paper offers guidance on how to interpret TSR in the light of SDL.

This paper thus not only aims to highlight TSR and SDL's potentially diverging relations, but also contributes to the foundation of a general theoretical TSR framework. By reviewing the current literature on SDL and TSR, the paper presents future research avenues for both approaches and provides a new perspective on the most recent perception of TSR.

\section{THE EMERGENCE OF TSR}

Since the early beginnings of mankind, humans have striven to improve their well-being and, hence, the quality of their lives. Well-being is not possible without service consumption (Ostrom et al., 2010). This may have taken the form of a caveman being tended to by a fellow clan member after being hurt during a mammoth hunt, or a patient currently undergoing radiotherapy treatment for cancer. (Re)Establishing well-being can either relate to the satisfaction of lower-level, basic needs through clean air, water, food, and the availability of a shelter (housing), or to a higher needs level where individuals satisfy needs, such as esteem needs to gain prestige, reputation, status, recognition, etc. (Maslow, 1943, 1987) through the type of (pent)house they own, the premium car they drive, and the high-end plastic surgeon they visit. In either way, consumption facilitates a myriad of purposes and consequences (Mick et al., 
2012). Originally, scholars contributed to consumer “well-being” by merely providing product testing and advice, after which scholarly consumer research emerged in the middle of the $20^{\text {th }}$ century. From these beginnings, transformative consumer research (TCR) evolved aimed at conducting research on the welfare of consumers, societies, and the environment at large (Mick, 2006). Recently, TCR has attracted new attention in order "to fill gaps and overcome some of the fragmentation and separation that characterize the field of consumer research in the essential domain of well-being” (Mick et al., 2012, p. 5).

Since service organizations have been and still are criticized for ignoring or harming consumer well-being (Rosenbaum et al., 2011), a rethinking process has been called for in service research to address the role services and service can play in enhancing and improving humans' lives rather than being potentially harmful or destructive (Anderson et al., 2013). Some research has started to concentrate on these well-being issues (e.g., Ozanne and Anderson, 2010; Rosenbaum et al., 2007), but many more services have well-being implications, such as financial services (see Anderson et al., 2013; Rosenbaum et al., 2011). Imagine the impact on the wellbeing of a family if, after a major disaster has struck a region, the family's house insurance delays paying out for years and blocks, or legally challenges, such payments, thus preventing the family from rebuild their home (e.g., InsuranceWatch, 2014; Peters, 2014). Likewise, how do we cater for vulnerable population - those often at the "base of the pyramid" (Gebauer and Reynoso, 2013, p. 482) with a low income - when household members face family violence, drug abuse, or children lack proper education. How can, for example, social services effectively reach those individuals and engage with them to improve their lives (Foote et al., 2014)? 


\section{TSR AND SDL}

In the TSR research strand, services and service are a means of improving individual well-being (e.g., of the consumer), as well as collective welfare (e.g., of society). TSR applies marketing tools and aims to "solve real problems" to improve the lives of these parties (Mick, 2006, p. 1). Anderson et al. (2013) propose a framework of four different dimensions to conceptualize research into well-being: service entities, consumer entities, the macroenvironment, and well-being outcomes. We next explain these four dimensions and relate them to Vargo and Lusch’s (2004, 2006, 2008a, 2008b) SDL approach.

\section{Service entities}

In TSR, service entities are service aspects with which other entities, such as consumers, interact and which can positively or negatively affect their well-being (Anderson et al., 2013). Service entities describe the supply side of a service, whether organizations, service sectors, employees of a service firm, service processes, or service offerings. Service entities engage with consumer entities on different system levels. On a micro level, it could be a service employee interacting with an individual customer. On higher levels, up to the macro level, it might be organizations or service sectors interacting with consumer entities. Using the systems level from the micro to the macro, these authors explain how the different levels of service entities in their framework may affect different levels of consumers.

SDL has been introduced as a lens or perspective to comprehend the social and economic world differently from the traditional microeconomic and related marketing-management view (Vargo, 2011), as it specifically emphasizes service as the foundation of all economic exchanges (Vargo and Lusch, 2008a). It views service employees as a type of operant resource (e.g., human actors) (Vargo and Lusch, 2004). These human actors possess knowledge and skills to activate, 
operate on, and integrate other available resources, for example, operand resources, which comprise machines or information. Service offerings are depicted as value propositions, as companies cannot deliver value, but only offer the potential to co-create value (Frow et al., 2014; Vargo and Lusch, 2008a). In SDL terminology, processes are understood as the use of one's resources, such as knowledge and skills, for the benefit of oneself and/or another entity, for example, another actor (Vargo and Lusch, 2008a). Hence, service is the basis of exchange. Organizations are regarded as part of a service system of resource integrating social and economic actors (Vargo and Lusch, 2008a). From its beginnings, SDL has been conceptualized as covering an unlimited broad range of industries (e.g., Vargo and Lusch, 2004) or sectors. Akaka, Vargo, and Lusch’s (2013) approach differentiates between the micro and the macro systems levels, in which actors engage in value co-creating activities on different levels of system complexity. These authors have begun to promulgate a service ecosystems approach. Service ecosystems are "relatively self-contained, self-adjusting systems of resource-integrating actors connected by shared institutional logics and mutual value creation through service exchange” (Vargo and Akaka, 2012, p. 207). Service ecosystems are therefore systems of service systems interacting with one another. For example, an organization called Whānau Ora employs an inclusive interagency approach to provide health and social services in order to develop the capacity of all New Zealand families in need. Whānau Ora empowers families as a whole, instead of merely focusing on individual family members’ issues and problems (Whānau Ora, 2014).

In summary, both TSR and SDL relate to entities or actors in a system where these facilitate, provide, and enable well-being and value to and for (other) entities or actors. Each of 
the approaches also applies a systems hierarchy, and the interacting entities or actors are part of this structure. Lower-level systems are embedded in higher-level ones.

\section{Consumer entities}

TSR regards consumer entities as individual consumers, collective consumer entities (such as families), social networks, communities, neighborhoods, cities, and nations (Anderson et al., 2011). While consumer entities represent different levels from the micro to the macro, the highest level being the ecosystem, which encompasses a system of human beings and nature. In such an ecosystem, service entities influence the environment and the consumer entities residing within it. Service entities’ interactions in the ecosystem affect them either positively or negatively. Conflicts between consumer entities may occur as a result of well-being efforts’ emphasis on a specific consumer entity (Anderson et al., 2013). For example, after a major disaster, emergency units might deal with the closest group of people. Although more distant groups of individuals or communities might need medical and other help more urgently, the current environmental conditions prevent the emergency units from reaching them.

SDL has developed an understanding of the value exchange across different groups of consumer entities or actors, such as business-to-business (B2B, e.g., Vargo and Lusch, 2011) and consumer-to-consumer (C2C, e.g., Finsterwalder and Kuppelwieser, 2011; Kuppelwieser et al., 2013). Recently, Vargo and Lusch (2011) have posited that there is a far more complex and dynamic system of actors who create value relationally. Hence, the term actor-to-actor (A2A) has been suggested to cater for the different actors at all levels - from the micro to the macro - in a service system (Vargo et al., 2008; Wieland et al., 2012). From this viewpoint, all actors are trying to improve their own well-being and viability (Wieland et al., 2012). This encompasses 
the individual customer's (service system’s) well-being (Vargo et al., 2008), as well as the entire service ecosystem’s well-being and survivability (Wieland et al., 2012).

If the approaches are compared, TSR currently propagates a holistic approach incorporating all types of consumer entities. SDL has likewise started to promote a comprehensive actor-to-actor view of "the existence of a much more complex and dynamic system of actors” (Vargo and Lusch, 2011, p. 182). Both approaches include different levels of entities or actors and their well-being or value co-creating efforts. TSR takes potential conflicts into consideration by facilitating well-being for entities within a service system. SDL regards well-being improvement - like any value co-creation process - as service-for-service exchange (Vargo and Lusch, 2008a).

\section{Macroenvironment}

TSR highlights the importance of the macroenvironment, namely the influence of public policy, cultural, technological, and economic environments, on consumer and service entities (Anderson et al., 2013). Anderson and colleagues (2013) highlight public policy’s importance, which can affect well-being and not always deliver the anticipated results. For example, according to its secondary education policy, New Zealand has to provide education for all children and, simultaneously, consider the cultural needs of ethnic groups, such as the Māori, Pacific Islanders, and other ethnicities (Ministry of Education, 2014).

In SDL, Vargo et al. (2008) refer to “system well-being” and view improvement in wellbeing as the system's adaptiveness, or ability to fit into its environment. In other words, the system’s environmental context determines its well-being: "Resources such as time, weather, and laws, which are often considered uncontrollable by the individuals and organizations, are integrated - if not relied on - in the value creation process by all service systems (e.g., 
customers, firms, families, countries)” (Vargo et al., 2008, p. 150). Edvardsson et al. (2011), as well as other authors (e.g., Epp and Price, 2011; Lepak et al., 2007), extend such view and consider the extended social system as the context for value co-creation. Edvardsson et al. (2011) contend that social structures play an important role in resource integration and value cocreation.

Both TSR and SDL regard the wider (macro) environment as an enabler or inhibitor of the co-creation of well-being and value within its boundaries. Whilst TSR views the macroenvironment as entities' boundaries and boundaries to well-being outcomes within the system, SDL highlights the entire system's well-being as a process of interaction with the environment, thus leading to system adjustment.

\section{Well-being outcomes}

The TSR approach provides a framework for consumers' and employees' well-being on an individual and collective level. Interaction between different entities establishes and maintains well-being (Anderson et al., 2013). In a very broad sense, interaction relates to any contact between service and consumer entities. TSR focuses on two types of well-being, eudaimonic and hedonic, and on consumer entities (Anderson et al., 2013).

Eudaimonic well-being describes the realization of potential. While Waterman (1984, p. 16) defines eudaimonia as "feelings accompanying behavior in the direction of, and consistent with, one's true potential," Haybron (2008, p. 21) labels its content "human flourishing." Anderson et al. (2013) apply eudaimonic well-being to the individual, collective, and ecosystems levels. Their list of eudaimonic well-being elements includes access to a service, literacy, better decision making, health, decreasing health and well-being disparities, consumer involvement, harmony, power, respect, support, and social networks. 
On the other hand, hedonic well-being is grounded in the ideas of happiness and "defines well-being in terms of pleasure attainment and pain avoidance” (Ryan and Deci, 2001, p. 141). Using the same rationale, Anderson et al. (2013) apply hedonic well-being to individual and collective levels. Elements of hedonic well-being are life satisfaction, positive affect, and the absence of negative affect, such as tension, fear, strain, and stress.

Examples of the two well-being categories are access to public health and social services, and working on improving the health and well-being of certain ethnicities to minimize disparity (eudaimonic well-being). Māori life expectancy, for example, is lower than that of non-Māori by about 3.5 years (Statistics New Zealand, 2014a). Pacific Islands children and young individuals (aged 0-24 years) are almost 50 times more likely than European children (and twice as likely as Māori) to be admitted to hospital with acute rheumatic fever. Pacific young people are approximately twice as likely to encounter depression, anxiety issues, or to attempt suicide as the rest of the population (Statistics New Zealand, 2014b).

Hedonic well-being relates to maintaining individual and collective happiness. New Zealand, for example, uses a general social wellbeing survey measuring life satisfaction, which includes factors such as relationships, money, and housing. For example, just over half of New Zealanders (52\%) report that they have more than enough or enough money to live on (Statistics New Zealand, 2014c). Housing seems to be a current issue and a topic of political debate and for policy makers (Davison, 2014).

Anderson et al. (2013) also refer to services positive' and negative outcomes. The provision of services may have intended positive outcomes for certain members of society, but negative unintended consequences for others. For example, social services may focus on providing services for certain ethnic groups and members of society, but do not actively target 
other ethnic minorities, who may feel "abandoned.” This may cause unintentional negative effects and tensions. Equally, on the one hand, providing social services may make service employees feel very productive and satisfied regarding their achievements and jobs when they increase their number of appointments with clients (consumer entities) considered "hard to reach” (Foote et al., 2014). On the other hand, these consumer entities may feel very unhappy with the service provision focusing on the quantity of compulsory appointments rather than the quality of the service provided, i.e. the help provided, and they may begin disengaging from the service provider (Foote et al., 2014).

Early scholars viewed all activities contributing to well-being as productive, which were therefore attributed with having value-in-use (Mill, 1929; Say, 1821). By adopting this view (Vargo and Lusch, 2008a), SDL's value tenet embodies human well-being and, on a collective or system level, value equates with improving the entire system’s well-being (Vargo et al., 2008). Here, value ("benefit") is the "increased (decreased) viability (wellbeing) of the system” (Vargo and Lusch, 2014, p. 29). In such a system, actors integrate their resources to create value for themselves and others (Vargo et al., 2008). Value is co-created contextually, and is experiential and meaning laden. The beneficiary, for example, the customer (actor) who is always a cocreator of value, determines this value uniquely and phenomenologically (Vargo and Lusch, 2008a). This implies that value creation is interactional. An actor can accept value propositions that another actor makes, for example, a service provider, which can only offer these propositions, but cannot create and/or deliver value independently (Vargo and Lusch, 2008a). Actors "relationally co-create value and (...) jointly provide the context through which 'value' gains its collective and individual assessment” (Vargo and Lusch, 2011, p. 182). SDL consistently applies a value concept, culminating in Vargo and Lusch’s (2008a, p. 5) value 
extension "to all entities that exchange to improve their own state of being (e.g., individuals, families, firms, societies, nations, etc.).” Vargo and Lusch (2008a) also note that SDL provides the grounds for ethical, social, and non-profit marketing.

By evaluating the perspectives, TSR's focus is on generating well-being for the different entities in the system. Similarly, SDL views value as the core concept of actors' well-being. Interaction, or some form of exchange, plays a central role in achieving well-being or co-created value in both concepts. Vargo and Lusch (2006, p. 43) state that “...in order to improve their individual and collective well-being, humans exchange the service - the application of specialized skills and knowledge - that they can provide to others for the service that they need from others.” Comparably, Anderson et al. (2013, p. 1204) posit that interaction "refers to any contact between service and consumer entities [which] ... includes interpersonal service encounters [and] ... any time a consumer entity, whether that be an individual, collective or the broader ecosystem, is exposed to any aspect of a service entity during value creation processes.” Here, TSR does not connect interaction and well-being directly, as it defines interaction very broadly.

Both approaches relate to different system levels, on which well-being and value can be co-created, by distinguishing between micro and macro systems levels. Whereas in SDL, value and value co-creation seems to relate to any possible value that actors co-create, TSR more specifically addresses individuals and collectives’ eudaimonic and hedonic well-being components. Additionally, TSR highlights the intended positive and unintended negative wellbeing outcomes. 


\section{EVALUATING THE TSR AND SDL PERSPECTIVES}

\section{Summarizing the Two Perspectives according to the Four Dimensions}

TSR and SDL both relate to service entities or actors on the "provider side," which facilitate co-creation for other entities, such as consumer entities or other actors. These entities or actors can interact with one another on different system levels. Equally, TSR and SDL refer to actors as "receivers" of service provision, whether they are called "consumer entities" (TSR) or "beneficiaries” (SDL). SDL disregards such distinction labeling all the entities involved as actors who integrate their resources. Both approaches view the macroenvironment as extant, with TSR referring to it as an enabler or inhibitor of well-being. SDL takes a system view and highlights service system viability, as well as viewing the system as part of a wider system and interacting with a multiplicity of other systems. In TSR and SDL, well-being outcome and value is cocreated through the interaction of the entities or actors on the various system levels for the benefit of the parties involved. TSR highlights two types of well-being outcomes: eudaimonic and hedonic. TSR also distinguishes between well-being efforts’ intentional and unintentional effects. Both approaches appear to be very similar when the four dimensions are used as a means of comparison.

\section{General Evaluation of TSR and SDL}

When TSR and SDL are further compared, the following points are taken into consideration:

Theoretical Focus. TSR aims at closing the gap left by transformative consumer research when addressing the role of service(s) by integrating consumer and service research into one another (Anderson et al., 2013). SDL aspires to develop a new perspective or view for the marketing and management disciplines (Vargo and Lusch, 2011). 
Practical Focus. TSR aims at solving "real problems” (Mick, 2006, p. 1). Anderson et al. (2013) list numerous examples and areas where TSR can be applied by specifically highlighting three of them (financial services, social services, and healthcare) without being exclusive. SDL aims at grounding a theory, but also a practice in service-dominant logic thinking; further SDL can be applied via mid-range theory (e.g., design thinking; blue ocean strategy) (Vargo and Lusch, 2014). Schulz and Gnoth (2008) state that SDL is an attitude and has to be understood before it can be applied to practical problems. For example, McColl-Kennedy et al. (2012) apply SDL to well-being by showing how customers can contribute to their value creation through their activities in managing their health care.

Positive vs. Negative Well-being or Value. In their 2011 TSR publication, Rosenbaum et al. (2011) note that the facilitation of some entities' well-being can be detrimental to the wellbeing of others. In respect of SDL, Vargo and Lusch (2008a) state that value is always co-created interactively. In the context of interactive value formation, Echeverri and Skålén (2011) suggest two possible outcomes of such interactive processes, which can result in value co-creation and value co-destruction outcomes.

Intentional vs. Unintentional Co-creation. TSR posits that intended value creation efforts to generate or improve well-being for some can also result in unintended well-being outcomes for others (Anderson et al., 2013; Rosenbaum et al., 2011). Vargo and Lusch (2008a) state that service-for-service exchange masks all interactions. Their approach is more "directional," as these interactions are either dyadic (direct service-for-service exchange), triadic (indirect servicefor-service exchange), or more complex (both direct and indirect service-for-service exchanges) (Chandler and Vargo, 2011). Lepak et al. (2007) relate to “intentionality of value co-creation”, a term this paper introduces, as value creation within and across system levels. Value co-creation 
is a different process at the societal level than at the individual or organizational level. Actors or sources "may act intentionally or unintentionally to create value for society at the same time they are creating value for themselves” (Lepak et al., 2007, p. 186).

Creation of Well-being or Value. TSR and SDL both focus on an interactional approach to well-being or value co-creation. Other authors mention that value creation can also be unilateral, actors can be either active or passive in the value creation process, and value can either be an activity-based or a mental experience (Heinonen et al., 2013).

"Logic" of the Approaches. TSR aims at transforming consumers' lives through service and services, which is founded on the human dignity concept (Anderson et al., 2013). TSR focuses on the well-being of consumer entities - individuals, communities, and the ecosystem. Hence, the transformational service perspective appears mostly consumer centric, especially because TSR professes to create "uplifting changes and improvements in the well-being" of those entities (Anderson et al., 2011, p. 3). Interestingly enough though, this new approach is inherently service centered, visible in its "branding” as transformative service research.” Vargo and Lusch (2004) state that their approach is the evolution from a goods-dominant logic to a service-dominant logic. Although Vargo and Lusch (2008a) suggest that the SDL perspective is inherently customer oriented and relational, service remains the underlying rationale. Consequently, the new logic is called "service-dominant logic". Are SDL and TSR thus service centric, because service is the underlying logic?

Some scholars have recognized this as an inaccuracy (e.g., Grönroos, 2006; Grönroos and Voima, 2013; Heinonen et al., 2010; Heinonen et al., 2013) and focus on customers and their roles in value creation. Service must ultimately be experienced by the customer (Vargo and Lusch, 2008a). More specifically, Heinonen and colleagues (2010; 2013) introduce a customer- 
dominant logic (CDL) as their perspective, and emphasize customers' ecosystem and their value's collective nature. They raise a number of customer-dominant challenges (Heinonen et al., 2013, p. 115), which include questions like "how do customers live their life?" and "what are the internal and external living contexts of customers?” For example, the question, "what are the challenges in the lives of customers?,” which takes a customer-oriented stance, could well be linked to the service-related question of Anderson et al. (2013, p. 1026): "How do service design and delivery decisions advantage or disadvantage individuals when compared to collectives?” Likewise, "what do customers feel," "what do customers enjoy," and "what delights/irritates the [sic] customers in their everyday life?” (Heinonen et al., 2013, p. 115) relate to TSR’s hedonic well-being component. Moreover, "what do the [sic] customers have a passion for and dream of?” (Heinonen et al., 2013, p. 115) is linked to eudaimonic well-being.

In SDL and TSR, interactions create value or well-being for entity/ies or actor/s, while for TSR - outcomes for others are inadvertent. For SDL and customer-dominant logic, TSR's well-being tenet appears to represent another approach to value and value (co-)creation. Table 1 provides a summary of the comparison of the TSR and SDL concepts.

Table 1 about here

\section{WHERE TO NOW?}

Undoubtedly, there is still much to discover in TSR and SDL and related research. SDL researches can look back on more than a decade of scholarly activity with the field remaining very active. Compared to this, TSR is in its very early stages. The first conceptual papers have been published (e.g., Anderson et al., 2013; Rosenbaum et al., 2011), most of which are of an 
exploratory, discovering, and risk taking nature (Fisk et al., 1993), and empirical work has started to appear (e.g., Mende and van Doorn, 2014). Thus, this paper suggests that there is no need to decide which of the approaches is more exclusive or inclusive, or more encompassing. This is instead a call to prevent compartmentalization, to make use of both concepts, and attempt integration or infusion. Both approaches can add to current knowledge and help provide progress in how we theorize about and apply value or well-being co-creation in service research in times of social change (Lefebvre, 2012). The crucial point is that both the theory and application of SDL and TSR should make a difference in people's lives. In the following, we highlight areas which deserve further development.

The first call is to further develop the theory. SDL appears to be evolving into a grand “theory.” Here, TSR can make use of concepts and perspectives already developed, such as systems thinking, and apply these to the micro and to the macro levels of the well-being concept. Moreover, theories can only build a bridge between the different schools of thought as well as between scholars and practitioners if there is a common understanding of these concepts and theories. Proliferation of new approaches requires clear definitions and a lexicon to avoid ambiguity and misunderstandings (Kohli, 2006; Vargo and Lusch, 2006). SDL has already undergone a process of refinement (e.g., Vargo and Lusch, 2008a), but more work needs to be done. TSR now has the opportunity to start its lexicon and focus on defining this research area. For example, the TSR definition's focus on “creating uplifting changes and improvements in the well-being of consumer entities” (Anderson et al., 2011, p. 3, italics added) needs further refinement. Should we refer to consumer entities (consumers and employees), or should we rather talk about citizens? It is important to contemplate how wide or narrow we delineate a research area and how we should define the terminology used in TSR? 
Second, both approaches - one further advanced, the other one in its infancy - require more application and connection to practice. More empirical work, such as specific cases on well-being (e.g., Mende and van Doorn, 2014) and value co-creation (e.g., McColl-Kennedy et al., 2012), but also the operationalization of constructs and concepts, is important. An increase in interdisciplinary collaboration would be highly beneficial for the concepts' theoretical and the practical advancement, as well as for dealing with resolving societal and environmental issues. Research projects which integrate researchers from different fields to work on a well-being or value co-creation topic (e.g., Foote et al., 2014) might be challenging, due to the different theoretical underpinnings and the researchers' various viewpoints of the subject matter. Nevertheless, these projects have the potential to create both new theoretical avenues and practical solutions suitable for the scholarly and applied progression of the consumer and service research field.

Third, positive and negative well-being or value has not received sufficient attention. Current studies are slowly gaining momentum (e.g., Echeverri and Skålén, 2011; Fisk et al., 2010; Grove et al., 1996; Mende and van Doorn, 2014; Plé and Chumpitaz Cáceres, 2010; Tombs and McColl-Kennedy, 2013). Service research is still not sufficiently focused on negative well-being outcomes, or value co-destruction, and their implications for individual actors or entities, as well as their effects on communities and society.

Related to this, the intentionality of well-being and value co-creation efforts needs much more attention. Unintended outcomes, which are potentially harmful, have to be more closely investigated, and measures need to be found to re-direct or contain such spill-over effects if detrimental to well-being and perceived value. Comparably, unintended positive outcomes have 
to be monitored, analyzed, evaluated, and potentially enhanced regarding creating a wider reaching well-being, or value-related effects on individuals, society, and the environment.

Furthermore, the formation or (co-)creation of value and well-being deserves more consideration. Different degrees of participation or activity in well-being or value co-creation efforts have not specifically been given enough thought. Additionally, how value or well-being is perceived requires more scholarly work in service research and service science.

Finally, it is important that the service dominance in both (the names of the) TSR and SDL concepts does not dilute their focus. Ultimately, it is the individual whose well-being and perceived value should be the centerpiece of service researchers' efforts. Individuals’ interaction with their environment, including other individuals and the wider ecosystem, influences individual well-being. This interconnectedness works both ways. Individual well-being contributes to societal well-being, while societal well-being enables individual well-being. Hence, the call is to focus on these actors or entities - individuals, communities, and societies.

Figure 1 presents an overview of the points mentioned above in an actor-centric approach. In light of further theory development and a focus on practical application, the upper part of Figure 1 shows a service system without transformational capability, or with only limited capability (c.f. Chandler and Vargo, 2011; Rosenbaum et al., 2011) due to the rigid boundaries that prevent the system from being flexible, agile, and fluid. A service system's transformational capability is the system's ability to flexibly adapt and change to altered or new requirements and, if necessary, to reconfigure itself by means of new actor and resource combinations. However, entities or actors within a rigid system such as the one depicted in Figure 1's upper part, may still be able co-create value and well-being for themselves and for others. Owing to its boundaries’ inflexibility, the system does not facilitate establishing connections with other systems (to the 
left and right in the top part of Figure 1). For example, legal, political, and even regional restrictions could prevent a social services provider from creating an encompassing network of service touch points, as well as partnerships with other providers, thus limiting service provision and well-being efforts' positive spill-over effects into other systems and vice versa. Nevertheless, within the system, actors / entities can connect with other actors / entities (indicated by the dotted lines) to co-create value or well-being, but the system's restrictions limit or slow down new connections with other entities or actors. Positive and negative, intentional and unintentional, value co-creation and well-being efforts, as well as outcomes, occur within the system boundaries where actors / entities actively or passively co-create value / well-being. The system might, however, have the potential to develop into a more fluid service system, as depicted in the lower half of Figure 1, for example, if the norms, rules, and regulations were to change (Edvardsson et al., 2011).

Figure 1 about here

The service system in the lower part of Figure 1 is a flexible and fluid one with a built-in transformational capability with permeable system boundaries. This system is agile and enables other service systems to connect to increase well-being, or value co-creation efforts, and outcomes for the actors / entities within it. For example, actor / entity $A_{O}$ within the service system connects with $A_{T}$ in another service system. Equally, actors within the system can create new linkages to other actors / entities (indicated by the dotted arrows). Well-being efforts' intentional spill-over effects can reach the other systems and an overarching system can monitor them, thus not only preventing a negative well-being outcome from spreading within the 
systems, but also from spreading to the neighboring systems. An example of such a fluid system is the above-mentioned organization, Whānau Ora, applying an interagency approach with a focus on collections of people rather than individuals.

\section{CONCLUSION}

While scholarly inquiries into the role of services and service outcomes are gaining momentum, current research is undecided regarding how to consider TSR in current thinking and existing research models. This paper connects TSR with SDL for a better understanding of their research aims and outcomes. In addition, this paper scrutinizes the connection between these concepts when TSR-related research is subsequently conducted.

Some limitations have to be kept in mind. The scope of this paper was to synthesize parts of SDL and TSR used in service research. This approach was "exclusive” and disregarded all other research fields in service and related sciences. Thus, this paper limits is predication to service research applications. However, TSR could gain a much broader scope in various other research fields, which SDL has already gained. Furthermore, this paper did not provide a comparison with social marketing (e.g., Russell-Bennett, Wood, et al., 2013; Russell-Bennett, Zainuddin, et al., 2013). Additionally, no closer assessment of customer-dominant logic (Heinonen et al., 2013) and TSR was undertaken, while other related concepts, such as the service logic by Grönroos (2006; Grönroos and Voima, 2013) were not taken into account. Scholars should strive to develop a coherent understanding of TSR and its relationships with these and other approaches.

Furthermore, this paper focuses on a comparison of SDL and TSR aspects. More research is needed to fully understand the complex relationships between the two concepts. 


\section{ACKNOWLEDGMENTS}

The authors would like to thank the participants of the ICCMI 2015 conference at Kingston University (London, UK) for their helpful discussion and comments. 


\section{References}

Akaka, M. A., Vargo, S. L., Lusch, R. F., 2013. The Complexity of Context: A Service Ecosystems Approach for International Marketing. Journal of International Marketing 21 (4), $1-20$.

Anderson, L., Ostrom, A. L., Bitner, M. J. (2011). Surrounded by Services: A New Lens for Examining the Influence of Services as Social Structures on Well-Being. working paper. Arizona State University. W. P. Carey School of Business.

Anderson, L., Ostrom, A. L., Corus, C., Fisk, R. P., Gallan, A. S., Giraldo, M., ... Williams, J. D., 2013. Transformative Service Research: An Agenda for the Future. Journal of Business Research 66 (8), 1203-1210.

Chandler, J., Vargo, S. L., 2011. Contextualization and Value-in-Context: How Context Frames Exchange. Marketing Theory 11 (1), 35-49.

Davison, I., 2014. Election 2014: Second Leaders' Debate. http://www.nzherald.co.nz/nz/news/article.cfm?c_id=1\&objectid=11317967 (accessed 16 September 2014).

Echeverri, P., Skålén, P., 2011. Co-Creation and Co-Destruction: A Practice-Theory Based Study of Interactive Value Formation. Marketing Theory 11 (3), 351-373.

Edvardsson, B., Enquist, B., 2008. Value-Based Service for Sustainable Business: Lessons from Ikea. New York, Routledge.

Edvardsson, B., Tronvoll, B., Gruber, T., 2011. Expanding Understanding of Service Exchange and Value Co-Creation: A Social Construction Approach. Academy of Marketing Science. Journal 39 (2), 327-339. 
Epp, A. M., Price, L. L., 2011. Designing Solutions around Customer Network Identity Goals. [Article]. Journal of Marketing 75 (2), 36-54.

Finsterwalder, J., Kuppelwieser, V. G., 2011. Co-Creation by Engaging Beyond Oneself: The Influence of Task Contribution on Perceived Customer-to-Customer Social Interaction During a Group Service Encounter. Journal of Strategic Marketing 19 (7), 607-618.

Fisk, R. P., Brown, S. W., Bitner, M. J., 1993. Tracking the Evolution of the Services Marketing Literature. Journal of Retailing 69 (1), 61-103.

Fisk, R. P., Grove, S. J., Harris, L. C., Keeffe, D. A., Daunt (née Reynolds), K. L., RussellBennett, R., Wirtz, J., 2010. Customers Behaving Badly: A State of the Art Review, Research Agenda and Implications for Practitioners. Journal of Services Marketing 24 (6), 417-429.

Foote, J., Baker, V., Carswell, S., Fa’asalele Tanuvasa, A., Finsterwalder, J., Hepi, M., . . . Taylor, A. (2014, 27 July - 01 August 2014). Towards a Service Ecology Approach to Improve Social Service Uptake and Outcomes for the ‘Hard to Reach' Populations. Paper presented at the Proceedings of the 58th Meeting of the International Society for the Systems Sciences - Learning Across Boundaries: Exploring the Variety of Systemic Theory and Practice, Washington DC.

Frow, P., McColl-Kennedy, J. R., Hilton, T., Davidson, A., Payne, A., Brozovic, D., 2014. Value Propositions: A Service Ecosystems Perspective. Marketing Theory 14 (3), 327-351.

Gebauer, H., Reynoso, J., 2013. An Agenda for Service Research at the Base of the Pyramid. Journal of Service Management 24 (5), 482-502.

Grönroos, C., 2006. Adopting a Service Logic for Marketing. Marketing Theory 6, 317-333. 
Grönroos, C., Voima, P., 2013. Critical Service Logic: Making Sense of Value Creation and CoCreation. Journal of the Academy of Marketing Science 41 (2), 133-150.

Grove, S. J., Fisk, R. P., Pickett, G. M., Kangun, N., 1996. Going Green in the Service Sector: Social Responsibility Issues, Implications and Implementation. European Journal of Marketing 30 (5), 56-66.

Haybron, D. M., 2008. Happiness, the Self and Human Flourishing. Utilitas 20 (1), 21-49.

Heinonen, K., Strandvik, T., Karl-Jacob, M., Edvardsson, B., Sundström, E., Andersson, P., 2010. A Customer-Dominant Logic of Service. Journal of Service Management 21 (4), 531-548.

Heinonen, K., Strandvik, T., Voima, P., 2013. Customer Dominant Value Formation in Service. European Business Review 25 (2), 104-123.

InsuranceWatch, 2014. Quake Rebuild Insurance Woes Relentless. http://insurancewatch.org.nz/docs/Press\%20Release\%20-\%20April\%207\%202014\%20Quake\%20Rebuild\%20Insurance\%20Woes\%20Relentless.pdf (accessed 10 September 2014).

Kohli, A. K., 2006. Invited Commentaries on the Service-Dominant Logic by Participants in the Otago Forum. Marketing Theory 6 (3), 290-291.

Kuppelwieser, V. G., Simpson, M. C., Chiummo, G., 2013. 1 + 1 Does Not Always Equal Value Creation: The Case of Youtube. Marketing Letters 24 (3), 311-321.

Lefebvre, R. C., 2012. Transformative Social Marketing: Co-Creating the Social Marketing Discipline and Brand. Journal of Social Marketing 2 (2), 118-129.

Lepak, D. P., Smith, K. G., Taylor, M. S., 2007. Value Creation and Value Capture: A Multilevel Perspective. [Article]. Academy of Management Review 32 (1), 180-194. 
Maslow, A. H., 1943. A Theory of Human Motivation. Psychological Review 50 (4), 370-396.

Maslow, A. H., 1987. Motivation and Personality. New York, Harper \& Row.

McColl-Kennedy, J. R., Vargo, S. L., Dagger, T. S., Sweeney, J. C., van Kasteren, Y., 2012.

Health Care Customer Value Cocreation Practice Styles. Journal of Service Research 15 (4), 370-389.

Mende, M., van Doorn, J., 2014. Coproduction of Transformative Services as a Pathway to Improved Consumer Well-Being: Findings from a Longitudinal Study on Financial Counseling. Journal of Service Research.

Mick, D. G., 2006. Presidential Address: Meaning and Mattering through Transformative Consumer Research. Advances in Consumer Research 33, 1-4.

Mick, D. G., Pettigrew, S., Pechmann, C., Ozanne, J. L., 2012. Origins, Qualities, and Envisionments of Transformative Consumer Research. In: Mick, D. G., Pettigrew, S., Pechmann, C., Ozanne, J. (Eds.), Transformative Consumer Research for Personal and Collective Well-Being. New York/London, Routledge, pp.

Mill, J. S., 1929. Principles of the Political Economy (1885), Reprint. London, Longmans, Green.

Ministry of Education, 2014. Policy and Funding Information. http://www.minedu.govt.nz/nzeducation.aspx (accessed 10 September 2014).

Ostrom, A. L., Bitner, M. J., Brown, S. W., Burkhard, K. A., Goul, M., Smith-Daniels, V., . . . Rabinovich, E., 2010. Moving Forward and Making a Difference: Research Priorities for the Science of Service. Journal of Service Research 13 (1), 4-36.

Ozanne, J. L., Anderson, L., 2010. Community Action Research. Journal of Public Policy \& Marketing 29 (1), 123-137. 
Peters, T., 2014. New Zealand: Three Years after the Christchurch Earthquake. http://www.wsws.org/en/articles/2014/02/22/chch-f22.html (accessed 10 September 2014).

Plé, L., Chumpitaz Cáceres, R., 2010. Not Always Co-Creation: Introducing Interactional CoDestruction of Value in Service-Dominant Logic. Journal of Services Marketing 24 (6), 430-437.

Rosenbaum, M. S., Corus, C., Ostrom, A. L., Anderson, L., Fisk, R. P., Gallan, A. S., .. . Williams, J. D., 2011. Conceptualization and Aspirations of Transformative Service Research. Journal of Research for Consumers (19), 1-6.

Rosenbaum, M. S., Ward, J., Walker, B. A., Ostrom, A. L., 2007. A Cup of Coffee with a Dash of Love: An Investigation of Commercial Social Support and Third-Place Attachment. Journal of Service Research 10 (1), 43-59.

Russell-Bennett, R., Wood, M., Previte, J., 2013. Fresh Ideas: Services Thinking for Social Marketing. Journal of Social Marketing 3 (3), 223-238.

Russell-Bennett, R., Zainuddin, N., Previte, J., 2013. The Value of Health and Wellbeing: An Empirical Model of Value Creation in Social Marketing. European Journal of Marketing 47 (9), 1504-1524.

Ryan, R. M., Deci, E. L., 2001. On Happiness and Human Potentials: A Review of Research on Hedonic and Eudaimonic Well-Being. Annual Review of Psychology 52 (1), 141-166.

Say, J., 1821. A Treatise on the Political Economy. Boston, Wells and Lilly.

Schulz, M., Gnoth, J. (2008). Understanding the Service-Dominant (S-D) Logic from within the Firm. Paper presented at the Otago Forum 2, Dunedin, New Zealand. 
Shirahada, K., Fisk, R. P., 2011. Broadening the Concept of Service: A Tripartite Value CoCreation Perspective for Service Sustainability. In: van der Rhee, B., Victorino, L. (Eds.), Advances in Service Quality, Innovation, and Excellence Proceedings of Quis12. Cortland, NY, Cayuga Press, pp. 917-926.

Statistics New Zealand, 2014a. Life Expectancy. http://www.stats.govt.nz/browse_for_stats/snapshots-of-nz/nz-socialindicators/Home/Health/life-expectancy.aspx (accessed 16 September 2014).

Statistics New Zealand, 2014b. Overall Health of Pacific Peoples in New Zealand. http://www.stats.govt.nz/browse_for_stats/people_and_communities/pacific_peoples/paci fic-progress-health/overall-health.aspx (accessed 16 September 2014).

Statistics New Zealand, 2014c. Social Well-Being in New Zealand 2012: Interactive Tool. http://www.stats.govt.nz/browse_for_stats/people_and_communities/Well-being/nzgss2012-interactive-tool.aspx (accessed 16 September 2014).

Thompson Reuters, 2014. Highly Cited Researchers in Economics and Business 2014. http://highlycited.com/ (accessed 10 September 2014).

Tombs, A. G., McColl-Kennedy, J. R., 2013. Third Party Customers Infecting Other Customers for Better or for Worse. Psychology and Marketing 30 (3), 277-292.

Vargo, S., Akaka, M. A., 2012. Value Cocreation and Service Systems (Re)Formation: A Service Ecosystems View. Service Science 4 (3), 207-217.

Vargo, S. L., 2011. On Marketing Theory and Service-Dominant Logic: Connecting Some Dots. Marketing Theory 11 (1), 3-8.

Vargo, S. L., Lusch, R. F., 2004. Evolving to a New Dominant Logic for Marketing. Journal of Marketing 68 (1), 1-17. 
Vargo, S. L., Lusch, R. F., 2006. Service-Dominant Logic: What It Is, What It Is Not, What It Might Be. In: Lusch, R. F., Vargo, S. L. (Eds.), The Service-Dominant Logic of Marketing: Dialog, Debate, and Directions. Armonk, NY, ME Sharpe, pp. 43-56.

Vargo, S. L., Lusch, R. F., 2008a. Service-Dominant Logic: Continuing the Evolution. Journal of the Academy of Marketing Science 36 (1), 1-10.

Vargo, S. L., Lusch, R. F., 2008b. Why “Service”? . Journal of the Academy of Marketing Science 36 (1), 25-38.

Vargo, S. L., Lusch, R. F., 2011. It's All B2b... and Beyond: Toward a Systems Perspective of the Market. Industrial Marketing Management 40 (2), 181-187.

Vargo, S. L., Lusch, R. F. (2014). Foundations \& Frontiers of Service-Dominant Logic. Paper presented at the Forum on Markets and Marketing, Karlstad, Sweden.

Vargo, S. L., Maglio, P. P., Akaka, M. A., 2008. On Value and Value Co-Creation: A Service Systems and Service Logic Perspective. European Management Journal 26 (3), 145-152.

Waterman, A. S., 1984. The Psychology of Individualism. New York, Praeger.

Whānau Ora, 2014. Te Puni Kōkiri - Realising Māori Potential. http://www.tpk.govt.nz/en/infocus/whanau-ora/ (accessed 18 September 2014).

Wieland, H., Polese, F., Vargo, S. L., Lusch, R. F., 2012. Toward a Service (Eco)Systems Perspective on Value Creation. International Journal of Service Science, Management, Engineering, and Technology 3 (3), 12-25. 
Table 1

Comparison of the Concepts of TSR and SDL

\begin{tabular}{|c|c|c|}
\hline Perspective & TSR & SDL \\
\hline \multirow[t]{5}{*}{ Service providers } & Service entities & $\begin{array}{l}\text { Resource integrators } \\
\text { (“beneficiaries”) / actors }\end{array}$ \\
\hline & Service employees & Operant resources / actors \\
\hline & Service offerings & Value propositions \\
\hline & Service processes & Service-for-service exchange \\
\hline & Service sectors & Service (eco)systems \\
\hline Service customers & Consumer entities & $\begin{array}{l}\text { Resource integrators } \\
\text { (“beneficiaries”) / actors }\end{array}$ \\
\hline System levels & From micro to macro systems & $\begin{array}{l}\text { From micro to macro (to meta) } \\
\text { systems }\end{array}$ \\
\hline Environment & $\begin{array}{l}\text { Macroenvironment influences } \\
\text { well-being }\end{array}$ & $\begin{array}{l}\text { System well-being is achieved } \\
\text { through adaptiveness to the } \\
\text { environment }\end{array}$ \\
\hline $\begin{array}{l}\text { Co-creation of well- } \\
\text { being / Value }\end{array}$ & $\begin{array}{l}\text { Creating uplifting changes and } \\
\text { improvements in the eudaimonic } \\
\text { and hedonic well-being of } \\
\text { consumer entities }\end{array}$ & $\begin{array}{l}\text { Enhancing actors' state of being } \\
\text { through value co-creation by means } \\
\text { of resource integration leading to } \\
\text { improved value-in-use / value-in- } \\
\text { context }\end{array}$ \\
\hline Interactivity & $\begin{array}{l}\text { Creation of well-being is an } \\
\text { interactional process }\end{array}$ & Value co-creation is interactional \\
\hline Impact & $\begin{array}{l}\text { Facilitation of well-being can } \\
\text { have negative impact on other } \\
\text { entities }\end{array}$ & $\begin{array}{l}\text { Resource integration can lead to } \\
\text { value co-creation or value co- } \\
\text { destruction }\end{array}$ \\
\hline Intentionality & $\begin{array}{l}\text { Directional and non-directional } \\
\text { well-being processes possible }\end{array}$ & $\begin{array}{l}\text { Directional value co-creation } \\
\text { processes }\end{array}$ \\
\hline Theoretical focus & $\begin{array}{l}\text { Integrating consumer and } \\
\text { service research }\end{array}$ & $\begin{array}{l}\text { New perspective for marketing and } \\
\text { management }\end{array}$ \\
\hline Practical focus & Solving real problems & Application via mid-range theory \\
\hline $\begin{array}{l}\text { "Logic" of } \\
\text { approaches }\end{array}$ & $\begin{array}{l}\text { Consumer centric; branding is } \\
\text { service centric }\end{array}$ & $\begin{array}{l}\text { Inherently customer orientated; } \\
\text { branding is service centric }\end{array}$ \\
\hline
\end{tabular}


Figure 1

Transformational Capabilities of a Service System

Rigid Service System with Fixed Boundaries and no / limited Transformational Capability

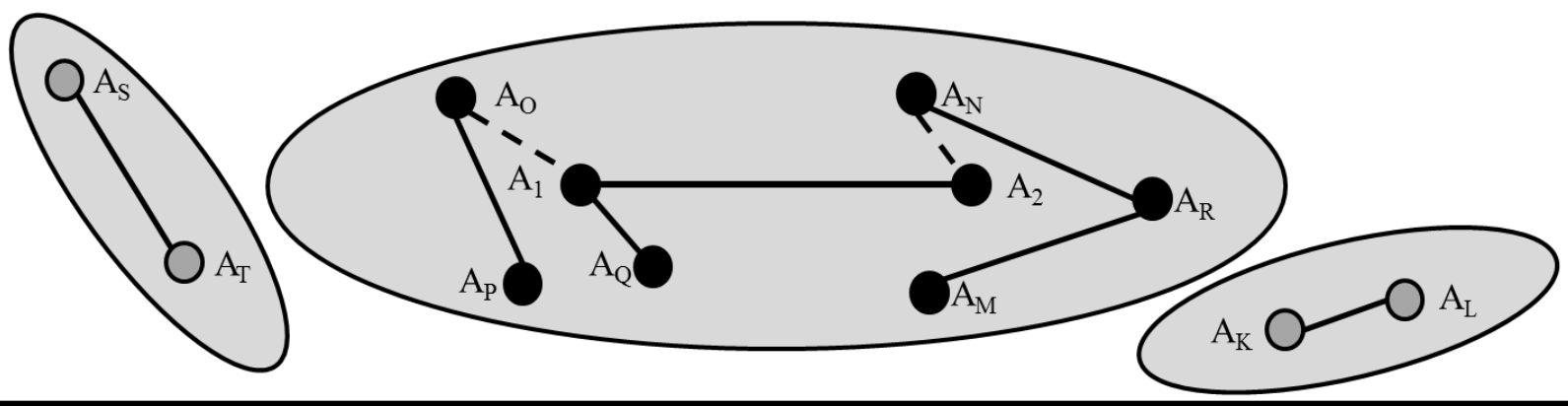

Fluid Service System with Permeable Boundaries and built-in Transformational Capability

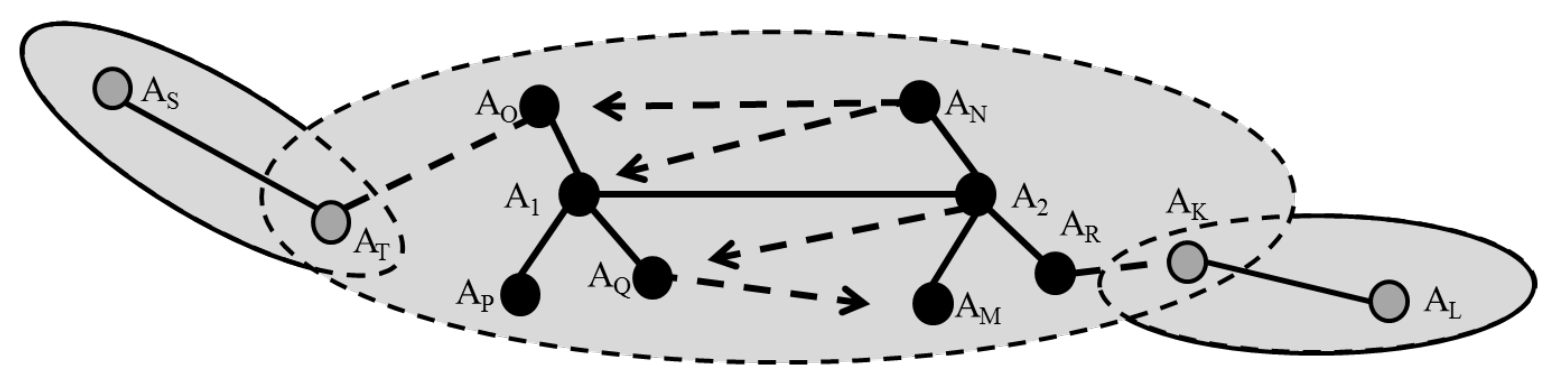

